Chapman University

Chapman University Digital Commons

Biology, Chemistry, and Environmental Sciences Science and Technology Faculty Articles and Faculty Articles and Research

2-25-2021

Plant Traits are Differentially Linked to Performance in a Semiarid Ecosystem

Jennifer L. Funk

Julie E. Larson

Joni Ricks-Oddie

Follow this and additional works at: https://digitalcommons.chapman.edu/sees_articles 


\section{Plant Traits are Differentially Linked to Performance in a Semiarid Ecosystem}

\section{Comments}

This is the accepted version of the following article:

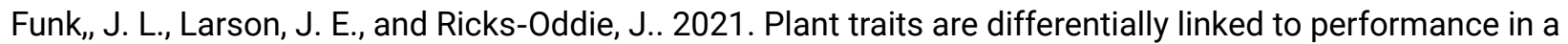
semiarid ecosystem. Ecology 102(5):e03318.

which has been published in final form at https://doi.org/10.1002/ecy.3318. This article may be used for non-commercial purposes in accordance with Wiley Terms and Conditions for Self-Archiving.

\section{Copyright}

Ecological Society of America 
DR. JENNIFER L. FUNK (Orcid ID : 0000-0002-1916-5513)

Article type : Articles

Journal: Ecology

Manuscript type: Article

Running head: Trait-performance relationships

Plant traits are differentially linked to performance in a semi-arid ecosystem

Jennifer L. Funk ${ }^{1,2,6}$, Julie E. Larson ${ }^{3}$, and Joni Ricks-Oddie ${ }^{4,5}$

${ }^{1}$ Schmid College of Science and Technology, Chapman University, Orange CA 92866

${ }^{2}$ Department of Plant Sciences, University of California, Davis, CA 95616

${ }^{3}$ Department of Ecology and Evolutionary Biology, University of Colorado, Boulder CO 80309

${ }^{4}$ Center for Statistical Consulting, University of California, Irvine CA 92797

${ }_{5}^{5}$ Institute for Clinical and Translation Sciences, University of California, Irvine CA 92797

${ }^{6}$ Corresponding author. E-mail: funk@ucdavis.edu

This article has been accepted for publication and undergone full peer review but has not been through the copyediting, typesetting, pagination and proofreading process, which may lead to differences between this version and the Version of Record. Please cite this article as doi: $\underline{10.1002 / \text { ECY.3318 }}$

This article is protected by copyright. All rights reserved 


\section{Abstract}

A central principle in trait-based ecology is that trait variation has an adaptive value. However, uncertainty over which plant traits influence individual performance across environmental gradients may limit our ability to use traits to infer ecological processes at larger scales. To better understand which traits are linked to performance under different precipitation regimes, we measured above- and belowground traits, growth, and reproductive allocation for four annual and four perennial species from a coastal sage scrub community in California under conditions of 50\%, 100\%, and 150\% ambient precipitation. Across water treatments, annual species displayed morphological trait values consistent with high rates of resource acquisition (e.g., low leaf mass per area, low root tissue density, high specific root length), and aboveground measures of resource acquisition (including photosynthetic rate and leaf $\mathrm{N}$ concentration) were positively associated with plant performance (reproductive allocation). Results from a structural equation model demonstrated that leaf traits explained $38 \%$ of the variation in reproductive allocation across the water gradient in annual species, while root traits accounted for only $6 \%$. Although roots play a critical role in water uptake, more work is needed to understand the mechanisms by which root trait variation can influence performance in water-limited environments. Perennial species showed lower trait plasticity than annuals across the water gradient and were more variable as a group in terms of trait-performance relationships, indicating that species rely on different functional strategies to respond to drought. Our finding that species identity drives much of the variation in trait values and trait-performance relationships across a water gradient may simplify efforts to model ecological processes, such as productivity, that are potentially influenced by environmentally-induced shifts in trait values.

Keywords: structural equation model, drought, photosynthesis, reproductive allocation, root traits, water availability, intraspecific trait variation, California

\section{Introduction}

The need for trait-based, predictive models of community and ecosystem function has never been greater. Climate change scenarios for many parts of the world include drier and more variable rainfall patterns compared to the last century (Cook et al. 2015), with potentially grave consequences for plant communities. Trait-based ecology offers a mechanistic and well-tested means of predicting 
how species and communities will respond to changing rainfall, based on the assumption that functional traits regulate long-term plant performance, reproductive output, and population growth rates (Violle et al. 2007, Adler et al. 2014). While a vast body of literature has enhanced our understanding how select leaf, seed, and whole-plant traits influence function (Díaz et al. 2016), many studies fail to consider how intraspecific trait variation relates to plant performance and how this variation drives processes at larger scales (Bolnick et al. 2011). Furthermore, less is known about how root traits impact growth, survival, and reproductive output across environmental gradients (Kramer-Walter et al. 2016, Laughlin et al. 2018). Identifying the traits that drive plant performance across different environments will enhance our ability to model how communities respond to a changing climate (e.g., Laughlin et al. 2012).

There are many ways that plants can succeed in drought-prone environments. The abundance of annual species in arid and semi-arid systems suggests that water conservation (e.g., robust tissues, water-use efficiency) is not the only lucrative strategy in these systems. By employing traits associated with high rates of resource acquisition (e.g., high photosynthetic rate, leaf nitrogen (N) content, specific root length) and growth, annual species can accelerate their phenology and complete reproduction before water limitation occurs (Kimball et al. 2013, Brouillette et al. 2014, Nguyen et al. 2016). This is consistent with a drought escape strategy (Levitt 1980, Ludlow 1989, Kooyers 2015, Volaire 2018). In contrast, perennial species adapted to low resource environments often remain active beyond the central growing season and employ traits associated with resource conservation, particularly in persistent stem and root tissues (Schenk and Jackson 2002, Thompson 2005). This is consistent with a drought avoidance or tolerance strategy (Levitt 1980), which we will collectively refer to as drought resistance. These different drought strategies often lead to large interspecific trait variation among coexisting annual and perennial species in water-limited systems (reviewed in Reich 2014). Trait variation also arises within annual and perennial groups. For example, annual species differ in their degree of stress tolerance (Angert et al. 2007, Harrison and LaForgia 2019, Valliere 2019) and perennial species can have divergent leaf phenology, ranging from evergreen leaves to winter- or drought-deciduous leaves that more closely resemble those of annual species. As many regions of the world experience altered rainfall patterns associated with climate change, there is an

This article is protected by copyright. All rights reserved 
urgent need to characterize how trait variation relates to drought response within and across coexisting species.

Relationships between traits and performance can vary across plant species (Dudley et al. 2012), resource availability gradients (Heschel et al. 2004, Donovan et al. 2009, Kimball et al. 2012 , Reich 2014, Laughlin et al. 2018), and plant age (Casper et al. 2005, Gibert et al. 2016). Additionally, different combinations of traits can result in equal performance in the same environment (Marks and Lechowicz 2006). Thus, in communities with a diversity of leaf types and life histories, it is unlikely that the same suite of traits correlates with performance across different precipitation scenarios for every species. Our understanding of how water availability impacts trait-performance relationships in annual species is largely restricted to a handful of leaf-level traits such as water-use efficiency, photosynthetic rate, leaf size, or leaf N concentration (Heschel et al. 2004, Donovan et al. 2009, Dudley et al. 2012, Kimball et al. 2013). Root traits are difficult to study and less is known about how they influence drought response outside of belowground biomass allocation (Bell and Sultan 1999, Poorter and Markesteijn 2008, Pérez-Ramos et al. 2013, Harrison and LaForgia 2019).

Similarly, trait-performance relationships are better characterized in annual species than in perennial species, for which performance can be difficult to quantify (Ackerly and Monson 2003). Our understanding of long-term responses to drought will benefit from comparative studies of multiple species that link leaf and root traits to different performance metrics, including growth and reproductive allocation.

In this study, we ask three questions. First, how do traits vary within and across annual and perennial species characterized by different drought strategies and exposed to different rainfall scenarios? Second, which traits are most strongly linked to performance? Finally, how do traitperformance relationships vary across water environments and species? To answer these questions, we measured a broad range of leaf and root traits, canopy volume, and reproductive allocation for four annual and four perennial species across three precipitation treatments in a southern California coastal sage scrub community. We expected to find trait values consistent with high rates of resource acquisition (e.g., high photosynthetic rate and specific root length, low leaf mass per area) in annual species irrespective of water treatment, as investing in resource conservation traits would inhibit an annual plant's ability to acquire resources for seed production (Heschel and Riginos 2005, Nguyen et 
al. 2016). Relative to annual species, we expected to find trait values more consistent with resource conservation (high water-use efficiency, root tissue density, root diameter) in perennial species, particularly with respect to root traits. We used a combination of correlation analysis and structural equation modeling to understand how traits related to plant performance (reproductive allocation), and multilevel models to determine how trait-performance relationships varied across species and water treatments.

\section{Materials and Methods}

Study species

We collected trait and performance data for four introduced annual species (Avena barbata, Brassica nigra, Bromus madritensis, Medicago polymorpha) and four native perennial species (Artemisia californica, Encelia californica, Isocoma menziesii, Salvia apiana) commonly found in coastal sage scrub systems. Coastal sage scrub, a Mediterranean-climate ecosystem, is found primarily along the coast of southern California and is characterized by a diverse matrix of native shrubs and herbaceous plants, along with a number of introduced annuals. Seedlings were propagated from seeds obtained the previous spring from individuals growing in wild and managed areas in Irvine, CA, except for B. nigra and M. polymorpha, which were obtained commercially. Seedlings (5 mo. old) of A. californica were obtained from a locally sourced nursery (Tree of Life Nursery, San Juan Capistrano, CA, USA).

\section{Experimental design}

To investigate plant traits and performance under different precipitation scenarios, we developed a rainfall manipulation experiment at the University of California South Coast Research and Extension Center in Irvine, CA $\left(33^{\circ} 41^{\prime} \mathrm{N}, 117^{\circ} 43^{\prime} \mathrm{W} ; 125 \mathrm{~m}\right.$ elevation, 330mm avg. annual precipitation). We established a $15 \mathrm{~m}$ x $30 \mathrm{~m}$ study site in a fallow field which was irrigated and disked to reduce weed growth and fenced to discourage herbivory. To manipulate rainfall, we constructed nine rain-out shelters ( $3 \mathrm{~m}$ width $\times 7.3 \mathrm{~m}$ length $\times 2.6 \mathrm{~m}$ height) with retractable clear plastic covers which were raised during major rainfall events to exclude precipitation. Site precipitation was monitored with a $1 \mathrm{~mm}$ resolution rain gauge (Decagon Devices, Pullman, WA, 
USA). Water was added to plots via irrigation systems installed in each structure (emitter height 1.5 $\mathrm{m}$; flow rate $14 \mathrm{~mm} \mathrm{hr}^{-1} ;>75 \%$ distribution uniformity). To monitor soil moisture status in the root zone, soil moisture sensors were installed at a depth of $15 \mathrm{~cm}$ (one EC-5 sensor per structure; Decagon Devices, Inc., Pullman, WA, USA). Soil texture, $\mathrm{pH}$, and nutrient concentrations were analyzed for three samples per structure. Soil methods and data are presented in Appendix S1.

In each shelter, we established eight $1 \mathrm{~m}^{2}$ plots containing one plant of each study species. Seedlings were transplanted at approximately 1 month old (except $A$. californica; see "Study Species") in December 2013, which corresponds with the beginning of the growing season. Any seedlings which died in the first month were immediately replanted. Species locations in each plot were randomized, with at least $30 \mathrm{~cm}$ between plants. Plots were weeded biweekly throughout the experiment to reduce external competition. In April 2015 (second year), we used a handheld light meter (LI-250A, LI-COR, Lincoln, NE, USA) to measure light at the top of the canopy for each shrub individual to assess the amount of shading due to neighboring plants (Appendix S1).

Watering treatments began in January 2014 after a one-month establishment period in which all plants received approximately $20 \mathrm{~mm}$ of precipitation. We randomly assigned each structure to one of three watering treatments: ambient precipitation (100\% of average January-April precipitation; $220 \mathrm{~mm}$ target), high precipitation (150\% of January-April average; $330 \mathrm{~mm}$ target), and low precipitation (50\% of January-April average; $110 \mathrm{~mm}$ target). Water was applied from January to April each year to achieve these targets (typically 2-3 times/week). Covers were then permanently retracted to allow ambient precipitation across treatments from May to December of each year. Rainfall into the uncovered plots was negligible during summer months (Appendix S1). In total, we had 72 replicate plants per species ( 3 treatments $x 3$ shelters $x 8$ plots). We lost several individuals to disease and drought during the experiment. Annual species B. nigra experienced the most mortality; of the original 72 individuals planted only 34 survived until the end of the experiment. The number of survivors was higher for other species: A. californica (65), A. barbata (72), B. madritensis (71), E. californica (71), I. menziesii (64), M. polymorpha (45), and S. apiana (51).

\section{Sampling}

This article is protected by copyright. All rights reserved 
Traits and reproductive data were sampled for all eight species in 2014 and for the four perennial shrubs in 2015 ( $1 \mathrm{yr}$ old at this time; annuals were not re-seeded). Canopy volume (height $\mathrm{x}$ canopy area) was assessed at the end of the growing season to coincide with maximum growth. While this metric has been found to correlate positively with aboveground biomass in our previous work with annual grasses (Nguyen et al. 2016), this metric could be limited as an assessment of aboveground biomass in shrubs due to variation in architecture under drought treatments. One recently mature leaf per plant was sampled for leaf photosynthetic capacity $\left(\mathrm{A}_{\text {area }}, \mu \mathrm{mol} \mathrm{m} \mathrm{m}^{-2} \mathrm{~s}^{-1}\right)$, transpiration rate $\left(\mathrm{E}, \mathrm{mol} \mathrm{m}^{-2} \mathrm{~s}^{-1}\right)$, stomatal conductance $\left(\mathrm{g}, \mathrm{mol} \mathrm{m}^{-2} \mathrm{~s}^{-1}\right)$, and quantum efficiency of photosystem II ( $\left.\Phi_{\text {PSII }}\right)$ with a LI-6400 portable photosynthesis system (LI-COR, Lincoln, NE, USA). Measurements were conducted between 08:00 and 13:00 local time with light levels at $2000 \mu \mathrm{mol}$ photon $\mathrm{m}^{-2} \mathrm{~s}^{-1}, \mathrm{CO}_{2}$ concentration at $400 \mu \mathrm{L} \mathrm{L}^{-1}$, and block temperature at $25 \mathrm{C}$. Flow rates through the chamber varied between 300 and $500 \mu \mathrm{mol} \mathrm{s}^{-1}$ to maintain a relative humidity between $40-60 \%$. $\Phi_{\text {PSII }}$ was calculated as $\left(\mathrm{F}_{\mathrm{m}}{ }^{\prime}-\mathrm{F}_{\mathrm{s}}\right) / \mathrm{F}_{\mathrm{m}}$, where $\mathrm{F}_{\mathrm{s}}$ is the fluorescence yield of a light-adapted leaf and $\mathrm{F}_{\mathrm{m}}{ }^{\prime}$ is the maximal fluorescence during a saturating light flash. When necessary, photosynthetic rates were temperature-corrected using standard equations (von Caemmerer 2000) and area-corrected to account for leaves that were too small to fill the chamber. Water use efficiency (WUE) was calculated as A/E. One recently mature leaf per plant was also sampled destructively to measure midday leaf water potential ( $\left.\Psi_{\text {leaf }}, \mathrm{MPa}\right)$ at least one day after any irrigation activity (Model 1000 pressure chamber, PMS instruments, Albany, OR, USA). Additional leaves were collected and scanned for leaf area, dried at $60^{\circ} \mathrm{C}$ for 3 days, weighed to calculate leaf mass per area (LMA; $\mathrm{g} \mathrm{m}^{-2}$ ), and ground for \% leaf $\mathrm{N}$ by mass using a Costech 4010 Elemental Combustion System (Costech Analytical Technologies, Valencia, California, USA).

Root trait data were collected from soil cores after all aboveground measurements were completed in April 2014 (annuals) or March-April 2015 (perennials). A $2 \mathrm{~cm} \mathrm{x} 20 \mathrm{~cm}$ soil core was taken approximately $3 \mathrm{~cm}$ from the base of five plants per species and structure (randomly selected). Actual core depth varied and was recorded to calculate sampled soil volume. All soil cores of a given species were collected on the same day, refrigerated, and processed within six days. Soil samples were rinsed through a $1 \mathrm{~mm}$ sieve to collect and scan root fragments for total root length, root volume, and average root diameter (WinRHIZO, Regent Instruments Inc., Quebec, Canada). Roots were then 
dried at $60 \mathrm{C}$ for 3 days and weighed. Root tissue density (RTD; $\mathrm{g} \mathrm{cm}^{-3}$ ) was calculated as root mass divided by root volume, root length density ( $\mathrm{RLD} ; \mathrm{cm} \mathrm{cm}^{-3}$ ) was calculated as root length divided by soil core volume, and specific root length (SRL; $\mathrm{m} \mathrm{g}^{-1}$ ) was calculated as the root length divided by root mass.

Species varied widely in reproductive morphology; thus, sampling protocols for reproductive allocation varied across species. Because we linked traits to reproductive allocation within individual species, our choice of different sampling protocols should not bias our results in any way. Reproductive allocation methods are described in Appendix S1.

\section{Statistical analysis}

All analyses were conducted in R (version 4.0.2). Single factor ANOVA was used to assess interspecific differences in light reaching the canopy surface and differences in soil variables across structures to check for effects of competition and soil function, respectively.

We used trait and reproductive data from 2014 for annuals and 2015 for perennials due to limited first year flowering in some perennials. Because we only had four annual and four perennial species, our analysis focuses on species-level differences rather than comparisons across annual/perennial groups. To partition the variance of traits by species and water treatment, we constructed a multilevel Bayesian model (Model 1) for each trait as follows:

$$
\mathrm{T}_{\mathrm{i}}=\beta_{0}+\beta_{\text {species }[\mathrm{i}]}+\beta_{\text {treatment }[\mathrm{i}]}+\beta_{\text {species } \times \text { treatment }[\mathrm{i}]}+\varepsilon_{\mathrm{i}}
$$

where $\mathrm{i}$ indexes each measurement, T is the trait value, $\beta_{0}$ is the population-level intercept, and $\beta$ is the group-level effect of species, treatment, and species-treatment interaction, respectively. Data were Z-scaled globally across species. The prior for the intercept term was distributed as Normal with mean of zero and standard deviation of two. The priors for the standard deviation terms were distributed as half-Cauchy with mean of zero and standard deviation of one. Estimated standard deviation of effects (Fig. 1) and estimated standardized species effect size on traits (Fig. 2) are reported from this model. To assess how trait-performance relationships were influenced by species and water treatment, we constructed a multilevel Bayesian model (Model 2) for each trait as follows:

$$
\mathrm{R}_{\mathrm{i}}=\beta \mathrm{T}_{\mathrm{i}}+\beta_{\text {species }[\mathrm{i}]} \times \mathrm{T}_{\mathrm{i}}+\alpha_{\text {treatment }[\mathrm{i}]}+\beta_{\text {treatment }[\mathrm{i}]} \times \mathrm{T}_{\mathrm{i}}+\varepsilon_{\mathrm{i}}
$$


where $\mathrm{i}$ indexes each measurement, $\mathrm{R}$ is reproductive allocation, $\mathrm{T}$ is the trait value, $\beta$ is the population-level trait effect, $\beta_{\text {species }}$ is the group-level trait effect per species, $\alpha_{\text {treatment }}$ is the grouplevel effect per treatment, and $\beta_{\text {treatment }}$ is the group-level trait effect per treatment. Traits and reproductive allocation were each z-scaled within species. Because of this scaling, we removed the species intercept terms from the model. The priors for the effect terms were distributed as Normal with mean of zero and standard deviation of two. The priors for the standard deviation terms were distributed as half-Cauchy with mean of zero and standard deviation of one. Effect sizes for the eight species and three water treatments are reported from this model (Fig. 4). Bayesian analyses were conducted using the 'brms' package in R (Bürkner 2017, Carpenter et al. 2017). To capture the variation in trait values across species and water treatments, plasticity indices (PIv) were calculated for each trait within a species as PIv $=($ maximum mean - minimum mean $) /$ maximum mean $)$ as in Valladares et al. (2006).

To assess covariation among above- and belowground traits and to visualize whether multivariate trait space responded to water treatments or differed across annual and perennials species, we used principal components analysis (PCA), excluding performance metrics ('psych' package in R). Analyses were conducted on standardized trait means for each species and water treatment. Axes were varimax-rotated and constrained to the first four components to improve axis interpretability.

We used structural equation modeling (SEM) to determine the relationships among traits and performance variables while explicitly accounting for relationships among traits ('lavaan' package in R; Rosseel 2012). Within a plant organ, traits can be highly correlated with each other (e.g., LMA and leaf $\mathrm{N}$ in leaves; tissue density and diameter in roots), although causal relationships among traits are often unclear (Mason et al. 2016). In contrast, there are fewer established links between aboveand belowground traits, or between multi-trait axes representing above- and belowground function (Bowsher et al. 2016, Kramer-Walter et al. 2016, Carvajal et al. 2019). Therefore, we hypothesized that traits could be used to define latent variables representing above- and belowground function, and that these variables are independently associated with plant performance. Estimation of these latent variables, through confirmatory factor analysis (Brown 2015), provides the ability to manage and minimize the measurement error associated with each measured trait and to use the shared 
information across traits to predict plant performance (Beran and Violato 2010). As larger plants have more resources available for reproduction (e.g., Farris and Lechowicz 1990), we hypothesized that traits influence reproductive allocation through direct effects of latent variables on canopy volume. We specified an initial model containing two latent variables (one describing aboveground function, one describing belowground function), canopy volume, and reproductive allocation. We then modified and refined the model to obtain a final model that converged and had good fit statistics; this process is described in the Results section. All traits were log-transformed prior to analysis. All structural equation models were estimated using full information maximum likelihood to address missing information (Enders 2010). Analyses were performed within annual ( $n=222$ individual plants) and perennial ( $\mathrm{n}=251$ individual plants) groupings across all water treatments to achieve a sufficiently large sample size for SEM. The SEM approach was more appropriate for our dataset than path analyses that used the individual traits as exogenous predictors of canopy volume and canopy volume as a predictor of reproductive allocation (see Appendix S1).

We also used correlation analyses to demonstrate relationships among traits and canopy volume. To examine relationships among traits and reproductive allocation for individual species and water treatment combinations, we produced posterior predictive check plots by overlaying the zscaled data atop the Model 2 fits.

\section{Results}

Across the growing season (January-May), soil volumetric water content (VWC) differed across the three treatments in both years (Appendix S1, p < 0.001). During the 2014 growing season, soil VWC averaged $18.3 \pm 0.1,19.8 \pm 0.1$, and $25.6 \pm 0.3 \%$ in the $50 \%, 100 \%$, and $150 \%$ treatments, respectively (error reported is standard error). In 2015, soil VWC averaged 17.4 $\pm 0.1,20.2 \pm 0.3$, and $22.7 \pm 0.4 \%$ in these treatments. Despite high variability in soil physical properties across the depth profile within a structure, soil variables did not differ across the nine structures (Appendix S1). Most perennial species experienced light levels similar to full sunlight at the canopy surface in 2015 when second year growth filled in plot canopies, although some individuals of S. apiana experienced higher degrees of shading (Appendix S1). We excluded heavily shaded S. apiana individuals from analyses.

This article is protected by copyright. All rights reserved 


\section{Inter- and intraspecific trait variation}

Species identity was a stronger driver of trait values than water treatment for several traits including leaf $\mathrm{N}$, light-use efficiency $\left(\Phi_{\mathrm{PSII}}\right)$, LMA, root tissue density (RTD), specific root length (SRL), root diameter $\left(\mathrm{R}_{\text {diam }}\right)$, and canopy volume (Fig. 1). Although species within annual and perennial groups were variable, perennials tended to have higher light-use efficiency, LMA, RTD, $\mathrm{R}_{\text {diam }}$, and canopy volume, but lower SRL compared to annuals (Fig. 2, Appendix S2). Stomatal conductance (g) and water-use efficiency (WUE) were more strongly impacted by water treatment than species identity (Fig. 1). Across species, reduced water availability generally led to lower $\mathrm{A}_{\text {area, }}$ $\mathrm{g}, \Psi_{\text {leaf }}$, and RLD, but higher WUE, LMA, and $\mathrm{R}_{\text {diam }}$ (Appendix S3). Canopy volume and reproductive allocation also decreased in all species with lower water availability except for $I$. menziesii (both metrics) and B. nigra (reproductive allocation only). Interactions between species identity and water treatment were sizable for g, $\Psi_{\text {leaf }}$, and RLD (Fig. 1). These interactions are best illustrated in Appendix S3, which shows standardized trait means for all species and treatments. Plasticity indices calculated across the three water treatments suggested that annual species displayed more trait plasticity than perennial species (Appendix S4). Furthermore, leaf physiology and fine root traits (SRL, RLD) were more variable across treatments while chemical and morphological traits (leaf $\mathrm{N}, \mathrm{LMA}, \mathrm{RTD}, \mathrm{R}_{\text {diam }}$ ) were less variable.

Across all species, PCA highlighted some potential trait tradeoffs across above- and belowground traits (Appendix S5). However, PCA largely confirmed species patterns presented in Fig. 2 (annual species clustering towards resource-acquisitive strategies on axes 1 and 3), and there were no signs of multivariate trait clustering by water treatment. Correlations among all traits for each species within low (50\%) and high (100 and 150\% combined) water treatments are provided in Appendix S6.

\section{Relationships between traits and plant performance}

The direction and magnitudes of trait-performance relationships for each species and water treatment are shown in Fig. 3. Differences in the slope of trait-performance relationships across species and water treatments are shown in Fig. 4 (traits included in SEM) and Appendix S7 (other 
traits); slopes are significantly different between species or treatments if the $95 \%$ credible intervals are not overlapping. Species identity impacted trait-performance relationships more strongly than water treatment (Fig. 4), so our discussion of these results focuses on species patterns. Leaf traits associated with resource acquisition ( $\mathrm{A}_{\text {area }}, \mathrm{g}$, leaf $\mathrm{N}$, light-use efficiency) were generally positively associated with performance in annual species (Fig. 3), and the slopes of these relationships were consistent across species (Fig. 4, Appendix S7). Furthermore, LMA showed consistent negative relationships with performance across annuals. Root traits and WUE were weakly correlated with performance in annuals with a few exceptions (Fig. 3, Fig. 4, Appendix S7). First, B. madritensis showed stronger trait-performance associations for RLD (positive) and $\mathrm{R}_{\text {diam }}$ (negative) relative to the other three annuals (Fig. 4). Second, RTD was negatively associated with performance in A. barbata. Collectively, these patterns suggest that a high resource acquisition strategy is favorable in annuals.

In contrast, we found positive associations between LMA and performance in three of four perennials (all except E. californica), positive associations between root structure $\left(\mathrm{R}_{\mathrm{diam}}, \mathrm{RTD}\right)$ and performance in S. apiana, a negative association between belowground foraging (RLD) and performance in I. menziesii, and more weakly positive associations between leaf-level carbon assimilation and performance in A. californica and I. menziesii relative to other species (Fig. 3, Fig. 4, Appendix S7). Collectively, these patterns suggest that investment in structure rather than carbon and resource assimilation is beneficial for perennials, although there is substantial variation across species. E. californica was a notable exception; this species was similar to annuals in having strong positive trait-performance relationships for leaf $\mathrm{N}$ and water potential along with a negative LMAperformance relationship.

Water availability did not significantly alter the slopes of trait-performance relationships (overlapping credible intervals in Fig. 4, Appendix S7), although the trends across water treatments are consistent with expectations. For example, metrics of water stress and leaf traits associated with conservation (high LMA, low $\mathrm{A}_{\text {area }}$, low leaf $\mathrm{N}$, low light-use efficiency) tended to be more strongly associated with performance in the low water treatment. Additionally, there was a trend for stronger associations between plant size and performance in low water treatments. Bivariate plots for standardized traits and reproductive allocation for all species in each water treatment are shown in Appendix S8.

This article is protected by copyright. All rights reserved 
Confirmatory factor analysis using full information maximal likelihood was used to estimate the above- and belowground latent variables in our structural equation model. Eight observed traits were initially included in the SEM; pared down from the 12 measured in the study to minimize covariation (e.g., g was excluded based on high correlation with $\mathrm{A}_{\text {area }}$ ). The original set of items used to estimate the aboveground factor were $\mathrm{A}_{\text {area }}, \mathrm{N}, \mathrm{LMA}$, and WUE. WUE was not included in the final aboveground factor due to its low factor loading. A likelihood ratio test comparing a model with WUE and one without WUE showed no significant difference between the models $\left(\chi^{2}(1)=0.5, p=\right.$ 0.48). $A_{\text {area }}$ and leaf $\mathrm{N}$ were positively related to the aboveground latent variable while LMA was negatively related (Fig. 5A). The traits used to estimate the belowground factor were $\mathrm{R}_{\text {diam }}, \mathrm{RTD}$, and RLD. The belowground trait SRL was not included in final model due to a highly skewed distribution resulting in negative residual variances. Several attempted transformations to correct the skew were unsuccessful. RTD and $\mathrm{R}_{\text {diam }}$ were positively related to the belowground latent variable while RLD was negatively related (Fig. 5B). The full hypothesized SEM included an above- and belowground latent variable predicting canopy volume, and canopy volume predicting reproductive allocation and was estimated separately for annual and perennial species.

The original proposed full model did not converge for either annual or perennial species. Thus, associations between above- and belowground traits and reproductive allocation were explored in separate aboveground (Fig. 5A) and belowground (Fig. 5B) latent variable models. The aboveground model for annuals had excellent fit $\left(\mathrm{CFI}=0.98\right.$; $\left.\operatorname{RMSEA}=0.073 ; \chi^{2}(2)=4.34\right)$. There

was a significant positive association between aboveground traits and reproductive allocation $(\beta=1.3$, $\mathrm{SE}=0.26, \mathrm{p}<0.001)$. Approximately $38 \%$ of the variability in reproductive allocation $\left(\mathrm{R}^{2}\right)$ was predicted by the aboveground latent variable. The belowground model for annuals fit less well (CFI = 0.89 ; $\left.\operatorname{RMSEA}=0.13 ; \chi^{2}(2)=9.27\right)$. There was a negative association between the belowground traits and reproductive allocation $(\beta=-1.65, \mathrm{SE}=0.94, \mathrm{p}=0.079)$. Approximately $6.4 \%$ of the variability in reproductive allocation $\left(\mathrm{R}^{2}\right)$ was predicted by the belowground latent variable. No SEM model converged for perennial species.

\section{Discussion}

This article is protected by copyright. All rights reserved 
Identifying traits that are strongly linked to performance across different water environments will enhance our ability to model ecological processes using increasingly available trait data (Funk et al. 2017a). Furthermore, because there are different modes of plant response to water limitation, characterizing common trait-performance patterns across species may allow ecologists to make general predictions for groups of species, such as annuals. Our results support our hypothesis that, irrespective of water treatment, annual species show values consistent with high rates of resource acquisition for some traits (high specific root length) while perennial species generally display trait values aligned with resource conservation (higher LMA, root diameter, root tissue density), although there was variation across species within these groups. Trait-performance patterns mirrored those of absolute trait values, with stronger associations between resource acquisition traits and reproductive allocation for annual species. For most species, leaf traits such as photosynthetic rate, leaf $\mathrm{N}$ concentration, and LMA showed stronger correlations with performance than root traits and water-use efficiency.

\section{Trait strategies of annual and perennial species}

While annual species in semi-arid environments are generally expected to exhibit a drought escape strategy, their functional traits can vary in significant ways (Mason and Donovan 2015, Harrison and LaForgia 2019). For example, desert annuals show trade-offs between growth and conservative water use, with important demographic consequences (Angert et al. 2007). Furthermore, annual species can display substantial intra- and interspecific trait variation associated with drought response, including greater resource acquisition (drought escape) in drier, low fertility sites (Rosenthal et al. 2010, Brouillette et al. 2014, Nguyen et al. 2016). In contrast, we found that four annuals were largely similar in their attributes and responses to variation in water availability. While annuals displayed a high degree of trait variation across the three water treatments, water treatment did not appear to be the dominant driver structuring trait-performance relationships (see below) or patterns of multivariate trait variation (i.e., trait variation along PCA axes), where broad species differences among annual and perennial groups were more clearly observed. Collectively, these data suggest that annual species in semi-arid systems invest in a resource acquisition strategy, even under stress. Although our study focused on four non-native annuals of regional management concern, 
native and non-native annuals in Mediterranean climates, including the study system used here, have been shown to have similar carbon capture strategies and trait values (Funk et al. 2016, Funk et al. 2017b). A critical next step will be to test whether trait responses to water availability characterized here also hold across a diversity of annual species.

In contrast to annuals, perennials were more variable as a group and displayed lower trait plasticity across water treatments. While leaf function tended to be more conservative in perennials on average (e.g., higher LMA), differences emerged in particular aspects of above- and belowground strategies. For example, E. californica and S.apiana maintained slightly higher photosynthetic rates than A. californica and I. menziesii, which are active longer in the growing season. Retaining thicker, longer-lived leaves may allow A. californica and I. menziesii to assimilate as much carbon as earlyseason flowering species with higher leaf-level photosynthetic rates. Separately, we observed wide variation in root traits, with E. californica and I menziesii creating thicker roots (higher root diameter, lower specific root length) with less foraging ability (lower root length densities) than $A$. californica and S. apiana, which had more acquisitive root systems. Thus, our data suggest that a "one-trait-fitsall” approach does not work for some plant groups, as species may rely on different functional strategies to maintain performance across different soil moisture environments.

\section{Are some traits more predictive of plant performance across species and water availability?}

Our structural equation model demonstrated that aboveground traits explained $38 \%$ of the variation in reproductive allocation in annual species - driven by positive associations among low LMA, high photosynthetic rate, high leaf $\mathrm{N}$, and performance - while root traits only accounted for $6.4 \%$. Similarly, while no model converged for perennial species, leaf traits showed stronger associations with reproductive allocation than root traits in these species, with the exception of relatively strong positive associations for root tissue density and diameter in S. apiana. Thus, aboveground traits appear to be better predictors of plant performance than the root traits examined here. The multilevel models showed that trait-performance relationships were more sensitive to species identity than to water availability; thus, our discussion of how specific traits influenced performance focuses on species-level patterns. The relationships between aboveground traits and performance varied across species, but these were largely consistent with expected trade-offs in 
resource acquisition and conservation. Leaf $\mathrm{N}$ and plant size showed strong positive associations with performance in several annual species, consistent with resource acquisition. In support of resource conservation in perennials, we found strong positive associations between LMA and performance in three of our four perennials (all except E. californica) and weak correlations between leaf-level carbon assimilation and performance in A. californica and I. menziesii.

Why are root traits poor predictors of plant performance in this system? Root traits are not as constrained by economic trade-offs as are leaves, and species have more flexibility in constructing roots (e.g., dense roots can be thick or thin) that are optimal for a particular environment (Bowsher et al. 2016, Kramer-Walter et al. 2016). Additionally, plants can increase rates of water uptake by modifying morphological traits (e.g., SRL, $\mathrm{R}_{\text {diam }}$ ), allocation traits (e.g., RLD), associations with microbial symbionts, or a combination of these traits. This leads to multidimensional axes of root function (Kramer-Walter et al. 2016, Weemstra et al. 2016) and potentially weak correlations between individual root traits and plant performance (Heschel et al. 2004). High root length density increases the volume of soil that plants can explore but, surprisingly, this trait was only positively correlated with plant performance in one of our four annual plants in certain water treatments, and one annual forb (B. nigra) actually showed decreased performance with high root length density in the low water treatment. Roots of some forb species can be less robust (e.g., low root dry matter content) than grass roots (Roumet et al. 2006, Larson et al. 2020), which could make it risky to invest in high root production if drought-induced root mortality leads to overall declines in plant water uptake.

We were also surprised to find weak correlations between plant performance and (1) root tissue density, which often aligns with resource acquisition and plant-level economic spectra (e.g., Kramer-Walter et al. 2016), (2) specific root length, which is purportedly the belowground analog of specific leaf area (Liu et al. 2010, Freschet et al. 2015), and (3) root diameter, which is often negatively correlated with specific root length (Kramer-Walter et al. 2016, Larson and Funk 2016). Weak correlations did not arise from low variation in root traits; coefficients of variation within species were similar across leaf and root traits (data not shown). Although root construction did not appear to enhance performance in most species, in the two instances where it did (B. madritensis and S. apiana), relationships largely appeared under favorable water conditions. This could implicate a threshold of resource availability where root traits can impact performance. If the soil profile is too 
dry, variation in rooting strategies may simply not matter, and performance may depend more on how plants use the water they have (e.g., leaf construction and physiology). However, in wetter environments, investing in less dense, thinner roots could lead to greater soil exploration and enhanced performance, as observed for B. madritensis. In the case of perennial S. apiana, we observed the opposite trend - denser, thicker roots led to enhanced performance in the high-water treatment. In this case, root diameter may be a proxy for rooting depth (Zhou et al. 2020), suggesting that deep-rooted shrubs avoid drought stress through greater access to water. Future comparative studies of root function could shed light on the functional significance of root traits by focusing on anatomical root traits or traits that influence water access at depth (e.g., rooting depth in perennials), which may be more predictive of plant performance in response to variation in water availability (e.g., Bowsher et al. 2016, Harrison and LaForgia 2019).

Traits related to tissue construction and carbon assimilation were more predictive of performance in annuals than water-use traits, including WUE. Our results contribute more evidence that the relationship between WUE and plant performance is not straightforward (Heschel and Riginos 2005, Donovan et al. 2009, Mason and Donovan 2015). WUE varied across the water gradient for all annual species, suggesting that short-lived plants can respond to variation in water availability by adjusting photosynthetic processes to conserve water or expedite growth, but this variation did not appear to benefit annual plants. Because plants can increase WUE in two ways, by increasing photosynthetic rate via greater investment in photosynthetic enzymes (i.e., higher leaf N; (Brouillette et al. 2014)) or by reducing transpiration rates, correlations between WUE and reproductive allocation may mask underlying mechanistic traits. Additionally, measures of WUE (i.e., $\mathrm{A} / \mathrm{g}, \mathrm{A} / \mathrm{E}, \delta^{13} \mathrm{C}$ ) are differentially sensitive to vapor pressure deficit and mesophyll conductance which means that measures may not be comparable across studies or even sites within a single study (Seibt et al. 2008). Given these limitations, we suggest that other traits, such as carbon assimilation traits $\left(\mathrm{A}_{\text {area }}\right.$, leaf $\mathrm{N}, \mathrm{g}$ ), leaf and stem hydraulic traits (reviewed in Reich, 2014), or leaf lifespan (in deciduous perennials), may be more informative when examining how species respond to changes in water availability.

\section{Implications for future work}

This article is protected by copyright. All rights reserved 
Trait-based frameworks that capture plant growth strategies (e.g., Díaz et al. 2016) may allow ecologists to measure a few traits on a large number of plants and generalize about how communities respond to changes in abiotic or biotic factors. However, the role of environment in altering both trait expression and adaptive value is rarely tested for multiple species. Our survey of annual and perennial species suggests that species identity (rather than water availability) drives much of the variation in trait values and trait-performance relationships across a water gradient. On one hand, this may simplify efforts to model ecological processes that could be influenced by environmentallyinduced shifts in trait values. However, it also suggests that future studies seeking to identify functional mechanisms of drought response would benefit from larger numbers of species, particularly for perennial species, in order to untangle the various pathways by which traits may confer advantages during drought.

Our use of reproductive allocation as a fitness metric, while arguably more relevant than vegetative biomass (e.g., Donovan et al. 2009, Kimball et al. 2012), does not incorporate offspring viability, seedling survival, and other vital rates that regulate population dynamics (Laughlin et al. 2020). Additionally, fitness in perennial species should be integrated over multiple years; one-time measures of plant performance are unlikely to capture changes in resource acquisition and use as plants shift allocation from leaves and roots to support tissues as they age (Poorter et al. 2012). For example, a 3-year longitudinal study of $A$. californica from our experiment found that intraspecific variation in leaf traits was more strongly influenced by plant age than by water availability (Funk et al. 2020). This suggests that, for shrubs, adding age-specific trait information into models may be more important than capturing trait shifts due to environment. Finally, aboveground traits that impact water use may be more predictive of important functions like productivity, while root traits may be more important for other processes not studied here, such as establishment (Harrison and LaForgia 2019, Larson et al. 2020).

\section{Acknowledgments}

We gratefully acknowledge N. Burtis, M. Christensen, J. Feinstein, K. Forrest, B. Galland, J. Kim, M. Macpherson, M. Merrill, K. Nguyen, M. Nguyen, A. Ortega, D. Platt, M. Rosenfield, N. Vorapharuek, G. Vose, and students from Orange High School for assistance in the field and 
laboratory, and C. Muir and one anonymous reviewer for constructive comments on the manuscript.

We thank D. Haver and C. Martinez at the South Coast Research and Extension Center. This work was funded by NSF-IOS 1256827. JLF planned and designed the research. All authors performed experiments and/or analyzed data. JLF was the primary writer, with edits from JEL and JRO.

\section{Supporting Information}

Additional supporting information may be found online at: [link to be added in production]

\section{Data Availability}

Data and source code (Macpherson and Funk 2020) can be found on Zenodo: https://doi.org/10.5281/zenodo.4312318

\section{References}

Ackerly, D. D., and R. K. Monson. 2003. Waking the sleeping giant: the evolutionary foundations of plant function. International Journal of Plant Sciences 164:S1-S6.

Adler, P. B., R. Salguero-Gomez, A. Compagnoni, J. S. Hsu, J. Ray-Mukherjee, C. Mbeau-Ache, and M. Franco. 2014. Functional traits explain variation in plant life history strategies. Proceedings of the National Academy of Sciences 111:740-745.

Angert, A. L., T. E. Huxman, G. A. Barron-Gafford, K. L. Gerst, and D. L. Venable. 2007. Linking growth strategies to long-term population dynamics in a guild of desert annuals. Journal of Ecology 95:321-331.

Bell, D. L., and S. E. Sultan. 1999. Dynamic phenotypic plasticty for root growth in Polygonum: a comparative study. American Journal of Botany 86:807-819.

Beran, T. N., and C. Violato. 2010. Structural equation modeling in medical research: a primer. BMC research notes 3:267-267.

Bolnick, D. I., P. Amarasekare, M. S. Araujo, R. Burger, J. M. Levine, H. W. R. Volker, S. J. Schreiber, M. C. Urban, and D. A. Vasseur. 2011. Why intraspecific trait variability matters in community ecology. Trends in Ecology and Evolution 26:183-192.

This article is protected by copyright. All rights reserved 
Bowsher, A. W., C. M. Mason, E. W. Goolsby, and L. A. Donovan. 2016. Fine root tradeoffs between nitrogen concentration and xylem vessel traits preclude unified whole-plant resource strategies in Helianthus. Ecology and Evolution 6:1016-1031.

Brouillette, L. C., C. M. Mason, R. Y. Shirk, and L. A. Donovan. 2014. Adaptive differentiation of traits related to resource use in a desert annual along a resource gradient. New Phytologist 201:1316-1327.

Brown, T. A. 2015. Methodology in the social sciences. Confirmatory factor analysis for applied research. Second edition. The Guilford Press.

Bürkner, P. C. 2017. brms: An R package for Bayesian multilevel models using Stan. Journal of Statistical Software 80:1-28.

Carpenter, B., A. Gelman, M. D. Hoffman, D. Lee, B. Goodrich, M. Betancourt, M. Brubaker, J. Guo, P. Li, and A. Riddell. 2017. Stan: A probabilistic programming language. Journal of Statistical Software:10.18637/jss.v18076.i18601.

Carvajal, D. E., A. P. Loayza, R. S. Rios, C. A. Delpiano, and F. A. Squeo. 2019. A hyper-arid environment shapes an inverse pattern of the fast-slow plant economics spectrum for above-, but not below-ground resource acquisition strategies. Journal of Ecology 107:1079-1092.

Casper, B. B., I. N. Forseth, and D. A. Wait. 2005. Variation in carbon isotope discrimination in relation to plant performance in a natural population of Cryptantha flava. Oecologia 145:541548.

Cook, B. I., T. R. Ault, and J. E. Smerdon. 2015. Unprecedented 21st century drought risk in the American Southwest and Central Plains. Science Advances 1:e1400082.

Díaz, S., J. Kattge, J. H. C. Cornelissen, I. J. Wright, S. Lavorel, S. Dray, B. Reu, M. Kleyer, C. Wirth, I. Colin Prentice, E. Garnier, G. Bönisch, M. Westoby, H. Poorter, P. B. Reich, A. T. Moles, J. Dickie, A. N. Gillison, A. E. Zanne, J. Chave, S. Joseph Wright, S. N. Sheremet'ev, H. Jactel, C. Baraloto, B. Cerabolini, S. Pierce, B. Shipley, D. Kirkup, F. Casanoves, J. S. Joswig, A. Günther, V. Falczuk, N. Rüger, M. D. Mahecha, and L. D. Gorné. 2016. The global spectrum of plant form and function. Nature 529:167-171.

Donovan, L. A., F. Ludwig, D. M. Rosenthal, L. H. Rieseberg, and S. A. Dudley. 2009. Phenotypic selection on leaf ecophysiological traits in Helianthus. New Phytologist 183:868-879.

This article is protected by copyright. All rights reserved 
Dudley, L. S., A. A. Hove, and S. J. Mazer. 2012. Physiological performance and mating system in Clarkia (Onagraceae): Does phenotypic selection predict divergence between sister species? American Journal of Botany 99:488-507.

Enders, C. K. 2010. Applied missing data analysis. Guilford Press, New York.

Farris, M. A., and M. J. Lechowicz. 1990. Functional interactions among traits that determine reproductive success in a native annual plant. Ecology 71:548-557.

Freschet, G. T., E. M. Swart, and J. H. C. Cornelissen. 2015. Integrated plant phenotypic responses to contrasting above- and below-ground resources: key roles of specific leaf area and root mass fraction. New Phytologist 206:1247-1260.

Funk, J. L., J. E. Larson, G. M. Ames, B. J. Butterfield, J. Cavender-Bares, J. Firn, D. E. Laughlin, A. E. Sutton-Grier, L. Williams, and J. Wright. 2017a. Revisiting the Holy Grail: Using plant functional traits to understand ecological processes. Biological Reviews 92:1156-1173.

Funk, J. L., J. E. Larson, and G. Vose. 2020. Leaf traits and performance vary with plant age and water availability in Artemisia californica. Annals of Botany.

Funk, J. L., M. A. Nguyen, R. J. Standish, W. D. Stock, and F. Valladares. 2017b. Global resource acquisition patterns of invasive and native plant species do not hold at the regional scale in Mediterranean type ecosystems. Biological Invasions 19:1143-1151.

Funk, J. L., R. J. Standish, W. D. Stock, and F. Valladares. 2016. Plant functional traits of dominant native and invasive species in Mediterranean-climate ecosystems. Ecology 97:75-83.

Gibert, A., E. F. Gray, M. Westoby, I. J. Wright, and D. S. Falster. 2016. On the link between functional traits and growth rate: meta-analysis shows effects change with plant size, as predicted. Journal of Ecology 104:1488-1503.

Harrison, S., and M. LaForgia. 2019. Seedling traits predict drought-induced mortality linked to diversity loss. Proceedings of the National Academy of Sciences 116:5576-5581.

Heschel, M. S., and C. Riginos. 2005. Mechanisms of selection for drought stress tolerance and avoidance in Impatiens capensis (Balsaminaceae). American Journal of Botany 92:37-44.

Heschel, M. S., S. E. Sultan, S. Glover, and D. Sloan. 2004. Population differentiation and plastic responses to drought stress in the generalist annual Polygonum persicaria. International Journal of Plant Sciences 165:817-824.

This article is protected by copyright. All rights reserved 
Kimball, S., J. R. Gremer, A. L. Angert, T. E. Huxman, and D. L. Venable. 2012. Fitness and physiology in a variable environment. Oecologia 169:319-329.

Kimball, S., J. R. Gremer, T. E. Huxman, D. Lawrence Venable, and A. L. Angert. 2013. Phenotypic selection favors missing trait combinations in coexisting annual plants. The American Naturalist 182:191-207.

Kooyers, N. J. 2015. The evolution of drought escape and avoidance in natural herbaceous populations. Plant Science 234:155-162.

Kramer-Walter, K. R., P. J. Bellingham, T. R. Millar, R. D. Smissen, S. J. Richardson, and D. C. Laughlin. 2016. Root traits are multidimensional: specific root length is independent from root tissue density and the plant economic spectrum. Journal of Ecology 104:1299-1310.

Larson, J. E., B. L. Anacker, S. Wanous, and J. L. Funk. 2020. Ecological strategies begin at germination: traits, plasticity, and survival in the first four days of plant life. Functional Ecology 34:968-979.

Larson, J. E., and J. L. Funk. 2016. Seedling root responses to soil moisture and the identification of a belowground trait spectrum across three growth forms. New Phytologist 210:827-838.

Laughlin, D. C., J. R. Gremer, P. B. Adler, R. M. Mitchell, and M. M. Moore. 2020. The net effect of functional traits on fitness. Trends in Ecology \& Evolution 10.1016/j.tree.2020.07.010.

Laughlin, D. C., C. Joshi, P. M. van Bodegom, Z. A. Bastow, and P. Z. Fule. 2012. A predictive model of community assembly that incorporates intraspecific trait variation. Ecology Letters 15:1291-1299.

Laughlin, D. C., R. T. Strahan, P. B. Adler, and M. M. Moore. 2018. Survival rates indicate that correlations between community-weighted mean traits and environments can be unreliable estimates of the adaptive value of traits. Ecology Letters 21:411-421.

Levitt, J. 1980. Responses of plants to environmental stresses, volume II: Water, radiation, salt, and other stresses. Academic Press, New York.

Liu, G., G. T. Freschet, X. Pan, J. H. C. Cornelissen, Y. Li, and M. Dong. 2010. Coordinated variation in leaf and root traits across multiple spatial scales in Chinese semi-arid and arid ecosystems. New Phytologist 188:543-553.

This article is protected by copyright. All rights reserved 
Ludlow, M. M. 1989. Strategies of response to water stress. Pages 269-281 in K. H. Kreeb, H. Richter, and T. M. Minckley, editors. Structural and functional responses to environmental stress. SPB Academic, The Hague, the Netherlands.

Macpherson, M. and J. Funk. 2020. jlfunk/funk-et-al-2021-ecology: First release (Version v1.0). Zenodo. http://doi.org/10.5281/zenodo.4312318

Marks, C. O., and M. J. Lechowicz. 2006. Alternative designs and the evolution of functional diversity. The American Naturalist 167:55-66.

Mason, C. M., and L. A. Donovan. 2015. Evolution of the leaf economics spectrum in herbs: Evidence from environmental divergences in leaf physiology across Helianthus (Asteraceae). Evolution 69:2705-2720.

Mason, C. M., E. W. Goolsby, D. P. Humphreys, and L. A. Donovan. 2016. Phylogenetic structural equation modelling reveals no need for an 'origin' of the leaf economics spectrum. Ecology Letters 19:54-61.

Nguyen, M. A., A. E. Ortega, Q. L. Nguyen, S. Kimball, M. L. Goulden, and J. L. Funk. 2016. Evolutionary responses of invasive grass species to variation in precipitation and soil nitrogen. Journal of Ecology 104:979-986.

Pérez-Ramos, I. M., F. Volaire, M. Fattet, A. Blanchard, and C. Roumet. 2013. Tradeoffs between functional strategies for resource-use and drought-survival in Mediterranean rangeland species. Environmental and Experimental Botany 87:126-136.

Poorter, H., K. J. Niklas, P. B. Reich, J. Oleksyn, P. Poot, and L. Mommer. 2012. Biomass allocation to leaves, stems and roots: meta-analyses of interspecific variation and environmental control. New Phytologist 193:30-50.

Poorter, L., and L. Markesteijn. 2008. Seedling traits determine drought tolerance of tropical tree species. Biotropica 40:321-331.

Reich, P. B. 2014. The world-wide 'fast-slow' plant economics spectrum: a traits manifesto. Journal of Ecology 102:275-301.

Rosenthal, D. M., V. Stiller, J. S. Sperry, and L. A. Donovan. 2010. Contrasting drought tolerance strategies in two desert annuals of hybrid origin. Journal of Experimental Botany 61:27692778.

This article is protected by copyright. All rights reserved 
Rosseel, Y. 2012. lavaan: An R package for structural equation modeling. Journal of Statistical Software 48:1-36.

Roumet, C., C. Urcelay, and S. Díaz. 2006. Suites of root traits differ between annual and perennial species growing in the field. New Phytologist 170:357-368.

Schenk, H. J., and R. B. Jackson. 2002. The global biogeography of roots. Ecological Monographs 72:311-328.

Seibt, U., A. Rajabi, H. Griffiths, and J. A. Berry. 2008. Carbon isotopes and water use efficiency: sense and sensitivity. Oecologia 155:441.

Thompson, J. D. 2005. Plant evolution in the Mediterranean. Oxford University Press, Oxford, UK. Valladares, F., D. Sanchez-Gomez, and M. A. Zavala. 2006. Quantitative estimation of phenotypic plasticity: bridging the gap between the evolutionary concept and its ecological applications. Journal of Ecology 94:1103-1116.

Valliere, J. M. 2019. Tradeoffs between growth rate and water-use efficiency in seedlings of native perennials but not invasive annuals. Plant Ecology 220:361-369.

Violle, C., M. Navas, D. Vile, E. Kazakou, C. Fortunel, I. Hummel, and E. Garnier. 2007. Let the concept of trait be functional! Oikos 116:882-892.

Volaire, F. 2018. A unified framework of plant adaptive strategies to drought: Crossing scales and disciplines. Global Change Biology 24:2929-2938.

von Caemmerer, S. 2000. Biochemical models of leaf photosynthesis. Csiro Publishing, Collingwood, Australia.

Weemstra, M., L. Mommer, E. J. W. Visser, J. van Ruijven, T. W. Kuyper, G. M. J. Mohren, and F. J. Sterck. 2016. Towards a multidimensional root trait framework: a tree root review. New Phytologist 211:1159-1169.

Zhou, Y., B. J. Wigley, M. F. Case, C. Coetsee, and A. C. Staver. 2020. Rooting depth as a key woody functional trait in savannas. New Phytologist 227:1350-1361.

This article is protected by copyright. All rights reserved 


\section{Figure legends}

Fig. 1. The estimated posterior distributions of variance components (in standard deviation) for effects of species, water treatment, and an interaction between species and treatment on observed traits using Model 1. Vertical lines are estimated posterior means, boxes are $50 \%$ posterior credible intervals, and thin lines are $95 \%$ posterior credible intervals. Trait abbreviations: Area-based photosynthetic rate $\left(\mathrm{A}_{\text {area }}\right)$; stomatal conductance $(\mathrm{g})$; leaf water potential ( $\left.\Psi_{\text {leaf }}\right)$; effective quantum yield of Photosystem II ( $\left.\Phi_{\text {PSII }}\right)$; water-use efficiency (WUE); leaf mass per area (LMA); root diameter $\left(\mathrm{R}_{\text {diam }}\right)$; root tissue density (RTD); root length density (RLD); and specific root length (SRL).

Fig. 2. Estimated species main effects on standardized trait values using Model 1. Vertical lines are estimated posterior means, boxes are 50\% posterior credible intervals, and thin lines are $95 \%$ posterior credible intervals. In each panel, the first four species are annual, the last four are perennial.

Fig. 3. Trait correlations with reproductive allocation for each species within water treatments. The area and hue of the circles are proportional to the value of the Pearson correlation coefficient. Blue indicates a positive correlation and orange indicates a negative correlation.

Fig. 4. Estimated effect sizes for species (blue) and water treatments (orange) on the relationship between traits and reproductive allocation using Model 2. Here we present results for the six traits included in the SEM. See Fig. S6 for other traits. Vertical lines are estimated posterior means, boxes are the $50 \%$ posterior credible intervals, and thin lines are $95 \%$ posterior credible intervals. In each panel, the first four species are annual, the last four are perennial.

Fig. 5. Structural equation model with standardized path coefficients and errors on data from 222 plants from four annual species for (A) aboveground and (B) belowground traits. Circles represent latent variables and rectangles represent measured variables. All paths are significant at $\mathrm{p}<0.05$. Model fit statistics are provided in the text.

This article is protected by copyright. All rights reserved 

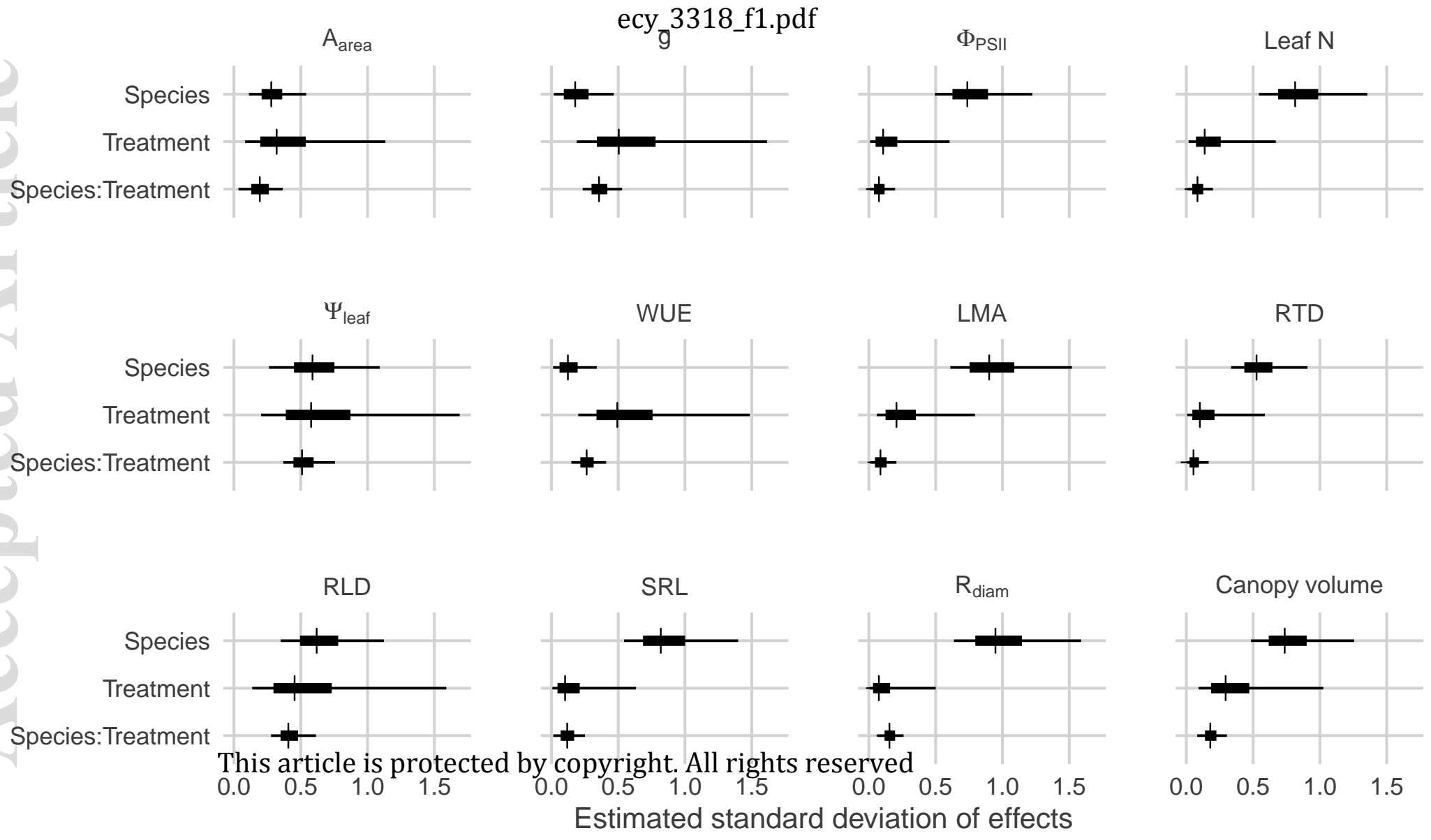


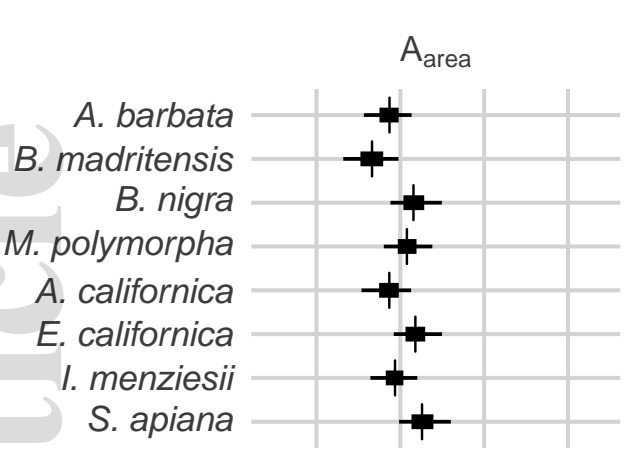

$$
\Psi_{\text {leaf }}
$$

A. barbata

B. madritensis

B. nigra

M. polymorpha

A. californica

E. californica

I. menziesii

S. apiana

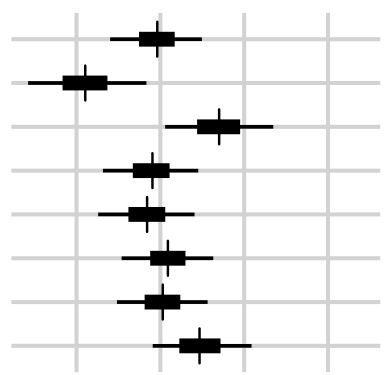

WUE
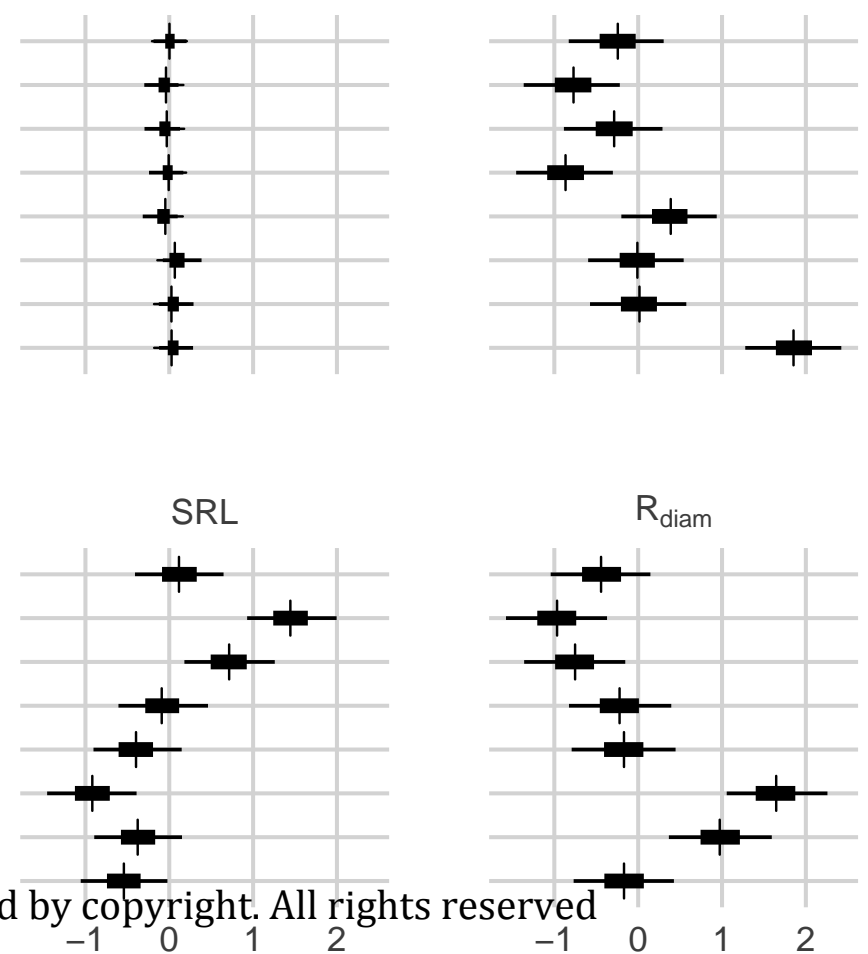

LMA

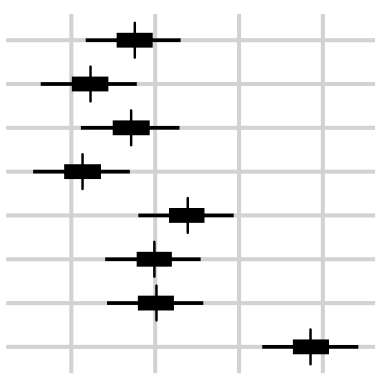

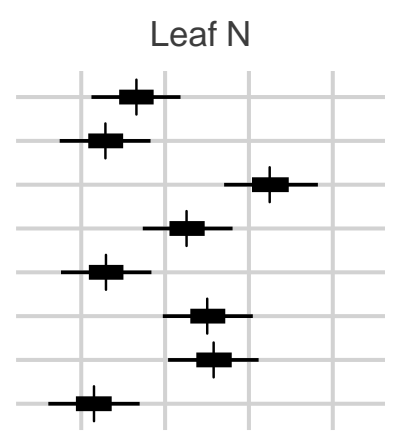

RTD

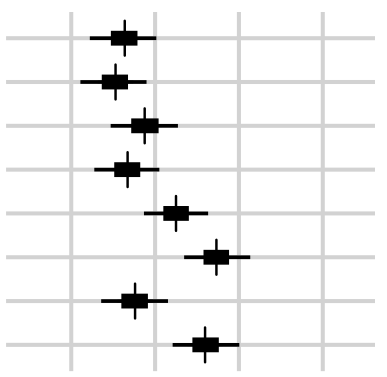

Canopy volume

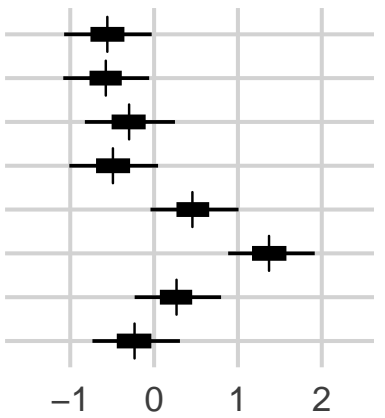

Estimated effect size of standardized trait 


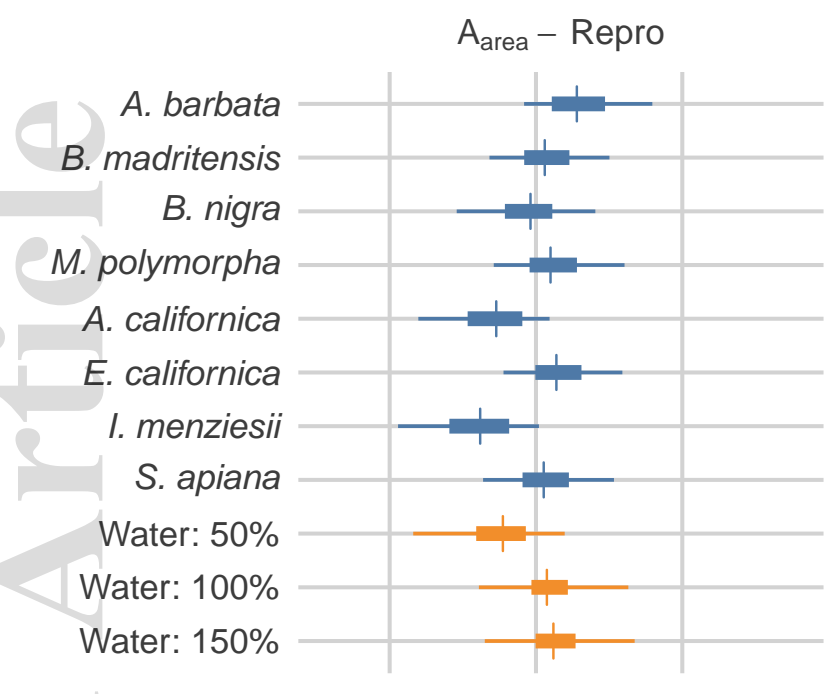

\section{ecy_3318_f4.pdff}

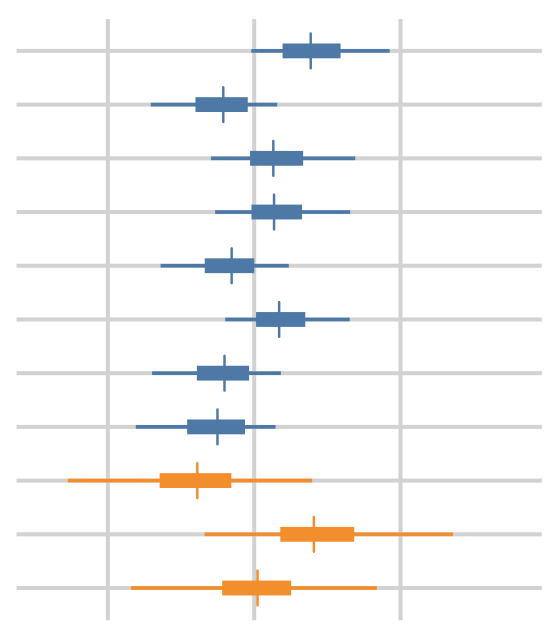

A. barbata

B. madritensis

B. nigra

M. polymorpha

A. californica

E. californica

I. menziesii

S. apiana

Water: $50 \%$

Water: $100 \%$

Water: $150 \%$

\section{RTD - Repro}

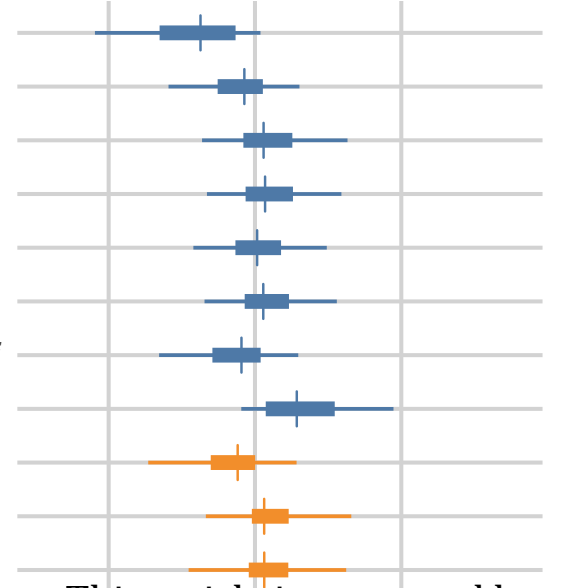

This article is protected by copyright. All rights reserved

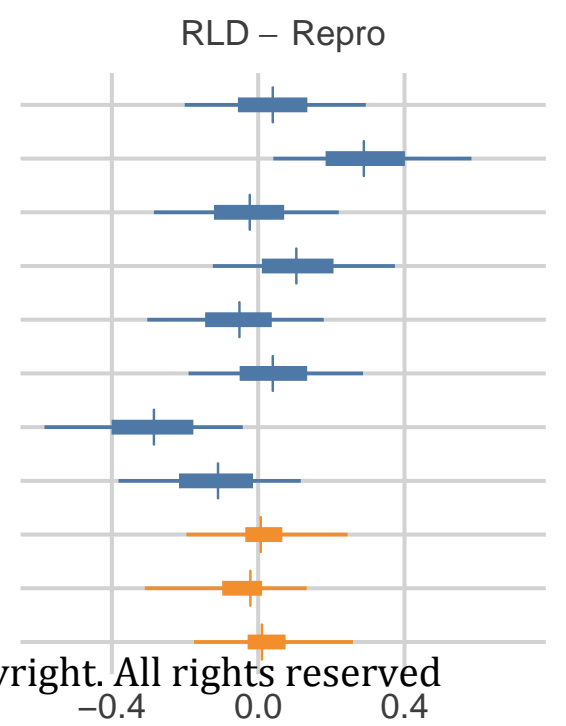

Estimated effect size
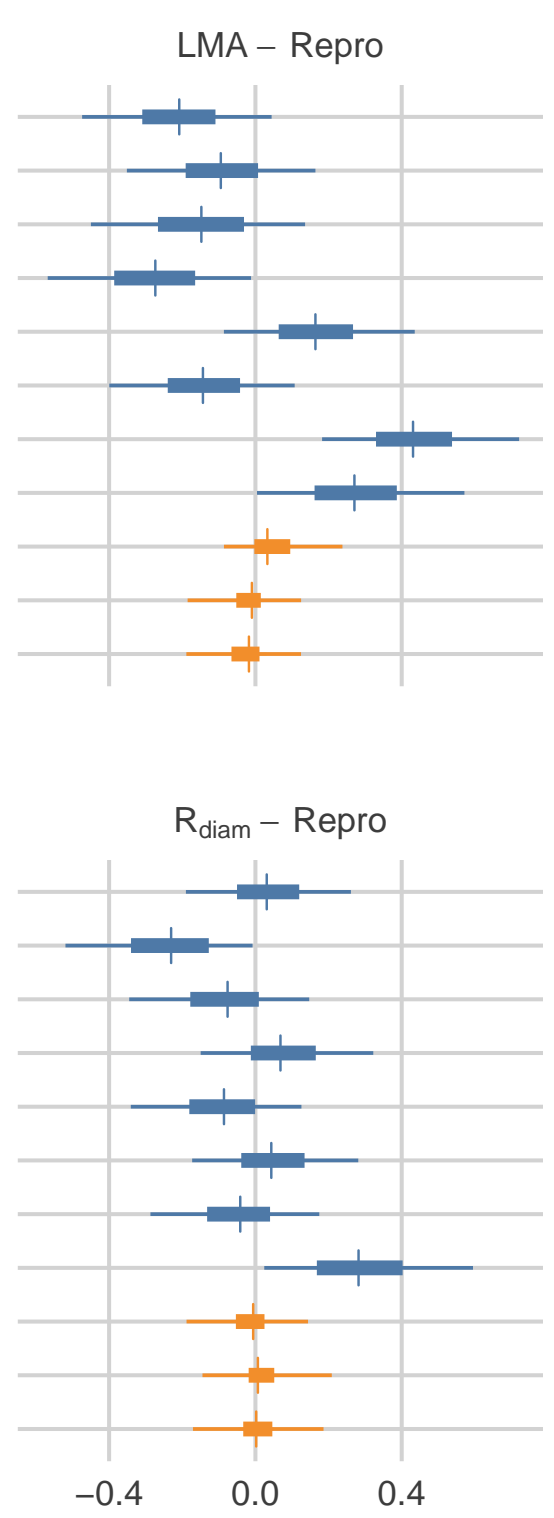
A.

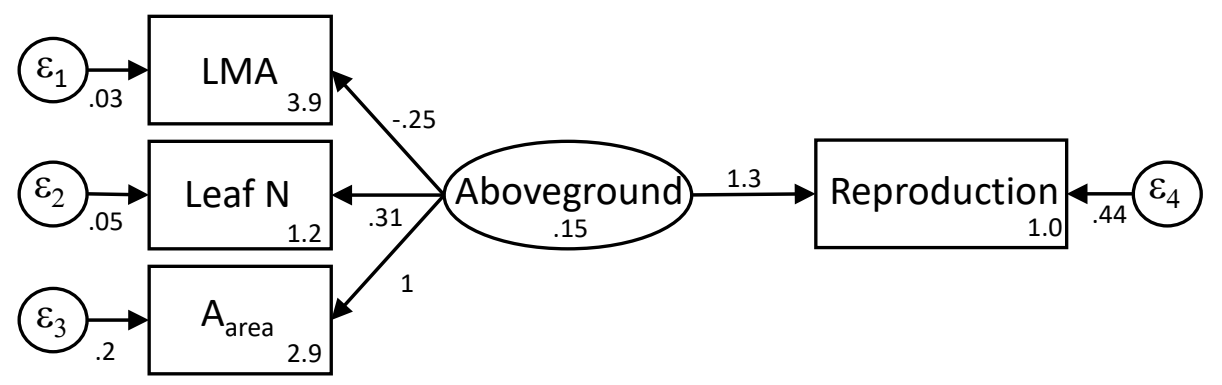

B.

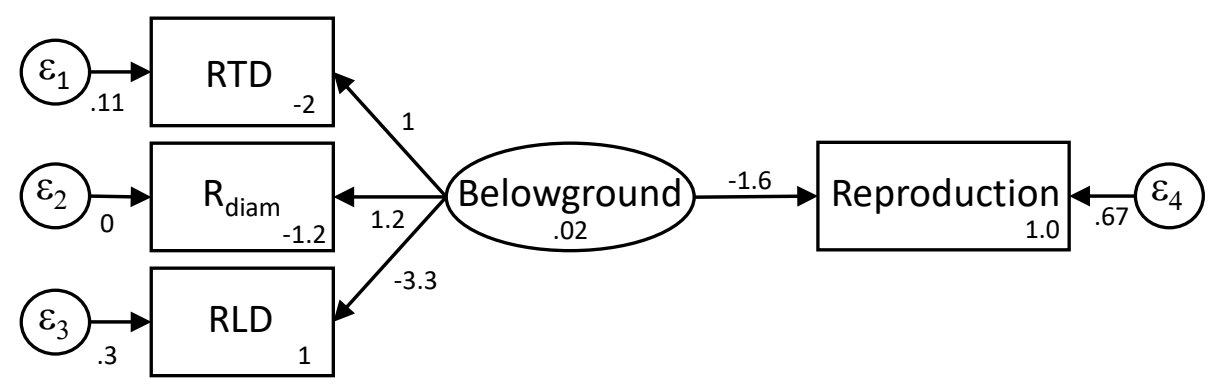

This article is protected by copyright. All rights reserved 